\title{
O FENÔMENO BULLYING NA EDUCAÇÃO FÍSICA ESCOLAR: UM ESTUDO DE CASO NO ENSINO MÉDIO
}

\author{
THE BULLYING PHENOMENON IN SCHOOL PHYSICAL EDUCATION: A CASE \\ STUDY IN MIDDLE SCHOOL
}

\author{
EL FENÓMENO BULLYING EN LA EDUCACIÓN FÍSICA ESCOLAR: UN \\ ESTUDIO DE CASO EN LA ENSEÑANZA MEDIO
}

\author{
Rodrigo José Madalóz ${ }^{1}$ Jéssica Renata Kupske Ebling ${ }^{2}$
}

\begin{abstract}
RESUMO
A pesquisa de caráter quanti-qualitativa caracterizou-se como um estudo de caso descritivo-interpretativo e objetivou investigar as manifestações de bullying em estudantes do Ensino Médio de uma escola pública de uma cidade da região das Missões/RS. A investigação partiu da seguinte problemática: quais experiências de bullying se manifestam nas aulas de Educação Física escolar com adolescentes do Ensino Médio? A população foi composta inicialmente por cem alunos. A coleta de dados foi realizada em dois momentos distintos: por meio de um questionário com perguntas abertas e fechadas no intuito de identificar possíveis vítimas de bullying nas aulas de Educação Física Escolar. Posteriormente por meio de uma entrevista semiestruturada com perguntas abertas, gravada e posteriormente transcritas, com quatro estudantes. A compreensão dos dados ocorreu por meio da categorização do conteúdo das entrevistas relacionadas às formas de agressão através do fenômeno bullying: manifestações de bullying por meio de violência verbal; manifestações de bullying por meio de violência psicológica e moral (agressões relacionadas ao corpo); e manifestações de bullying por falta de habilidades corporais. $\mathrm{O}$ conteúdo das entrevistas revelou os momentos e situações onde os (as) estudantes sofreram xingamentos e gozações de outros (as) estudantes em aula. As falas das vítimas apontam que mesmo de forma velada, o que acontece dentro e fora de grande parte das escolas, comprova que há ocorrências do fenômeno bullying nas escolas brasileiras.
\end{abstract}

PALAVRAS-CHAVE: Adolescência. Bullying. Educação Física Escolar. Ensino Médio.

\section{ABSTRACT}

The quantitative-qualitative research was characterized as a descriptive-interpretative case study and aimed to investigate the manifestations of bullying in high school students of a public school in a city of the Missões / RS region. The investigation started from the following problematic: what experiences of

\footnotetext{
${ }^{1}$ Doutor e Mestre em Educação pelo Programa de Pós Graduação em Educação da Universidade de Passo Fundo; Especialista em Educação Física Escolar (UNIVATES, 2004); Graduado em Educação Física (UPF, 1999). Docente na Universidade Regional Integrada do Alto Uruguai e das Missões (URI Santo Ângelo) no curso de Educação Física - Licenciatura e Bacharelado. Integra o Corpo Docente do curso de Pós-Graduação em Arteterapia na disciplina de Danças Circulares Sagradas e do curso de Pós-Graduação em Educação Infantil: Currículo e Infância (UPF). Integra o Corpo Docente do curso de Pós-Graduação em Personal Training do curso de Educação Física- URI Campus Santo Ângelo; Membro pesquisador do Grupo de pesquisa GIEF (Grupo Interdisciplinar de Educação Física da URI - Campus de Santo Ângelo). Docente do componente curricular Educação Física da rede pública estadual de ensino do RS. Docente substituto no Instituto Federal Farroupilha Campus de Santo Ângelo. Atua como assessor pedagógico do Programa União Faz a Vida - Sicredi.

${ }^{2}$ Licenciada em Educação Física pela Universidade Regional Integrada do Alto Uruguai e das Missões Campus Santo Ângelo - RS.
}

\begin{tabular}{l|l|l} 
Rev. Ciências Humanas & Frederico Westphalen, RS & Jan./abr. 2019
\end{tabular}

\begin{tabular}{l|l|l} 
Recebido em: 31/03/2019 & Aceito em: 26/04/2019 & Pg. $98-114$
\end{tabular}




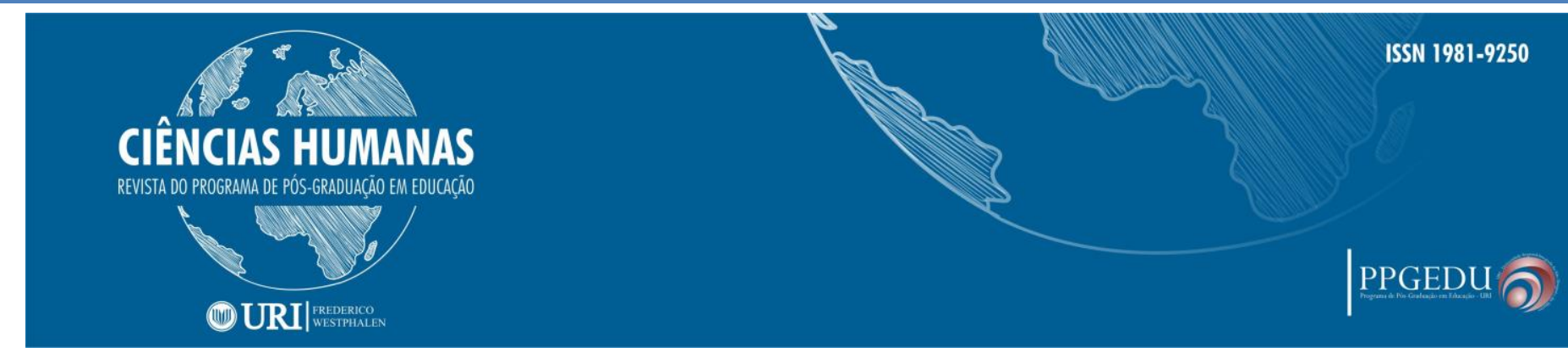

bullying manifest in the classes of Physical Education school with adolescents of the High School? The population was initially composed of one hundred students. The data collection was carried out in two different moments: through a questionnaire with open and closed questions in order to identify possible victims of bullying in the classes of Physical Education School. Subsequently through a semistructured interview with open questions, recorded and later transcribed, with four students. The understanding of the data occurred through the categorization of the content of the interviews related to the forms of aggression through the bullying phenomenon: manifestations of bullying through verbal violence; manifestations of bullying through psychological and moral violence (body-related aggressions); and manifestations of bullying for lack of bodily abilities. The content of the interviews revealed the moments and situations where the students were cursed and enjoyed by other students in class. The statements of the victims point out that even in a veiled way, what happens inside and outside most schools, proves that there are occurrences of the bullying phenomenon in Brazilian schools.

KEYWORDS: Adolescence. Bullying. Physical School Education. High School.

\section{RESUMEN}

La investigación de carácter cuantitativo se caracterizó como un estudio de caso descriptivo-interpretativo y objetivó investigar las manifestaciones de bullying en estudiantes de la Enseñanza Media de una escuela pública de una ciudad de la región de las Misiones / RS. La investigación partió de la siguiente problemática: ¿qué experiencias de bullying se manifiestan en las clases de Educación Física escolar con adolescentes de la Enseñanza Media? La población fue compuesta inicialmente por cien alumnos. La recolección de datos fue realizada en dos momentos distintos: por medio de un cuestionario con preguntas abiertas y cerradas con el propósito de identificar posibles víctimas de bullying en las clases de Educación Física Escolar. Posteriormente por medio de una entrevista semiestructurada con preguntas abiertas, grabadas y posteriormente transcritas, con cuatro estudiantes. La comprensión de los datos ocurrió por medio de la categorización del contenido de las entrevistas relacionadas a las formas de agresión a través del fenómeno bullying: manifestaciones de bullying por medio de violencia verbal; manifestaciones de bullying por medio de violencia psicológica y moral (agresiones relacionadas al cuerpo); y manifestaciones de bullying por falta de habilidades corporales. El contenido de las entrevistas reveló los momentos y situaciones donde los estudiantes sufrieron insultos y goce de otros estudiantes en clase. Las palabras de las víctimas apuntan que incluso de forma velada, lo que sucede dentro y fuera de gran parte de las escuelas, comprueba que hay ocurrencias del fenómeno bullying en las escuelas brasileñas.

PALABRAS CLAVE: Adolescencia. Intimidación. Educación Física Escolar. Enseñanza Media.

\section{CONSIDERAÇÕES INICIAIS}

O bullying é uma prática antiga. Até a década de 70 pouco se deu atenção a acontecimentos envolvendo esta prática, geralmente as vítimas apresentam receio e medo de represálias. Foi a partir de então que a sociedade começou a se preocupar com o fenômeno e com suas consequências (ARMANI; SILVA; ROSA, 2008). A palavra bullying é de origem inglesa e é adotada por diversos países para definir o desejo consciente de maltratar outra pessoa e expô-la a algum tipo de tensão (FANTE, 2005).

O bullying é um termo usado mundialmente, uma vez que não há tradução para esta palavra, todavia, é derivada da palavra bully, que pode ser entendida como

\begin{tabular}{l|l|l} 
Recebido em: 31/03/2019 & Aceito em: 26/04/2019 & Pg. 98 - 114
\end{tabular}




\section{CIÊNCIAS HUMANAS}

REVISTA DO PROGRAMA DE PÓS-GRADUAĞ̈O EM EDUCAĞ̄o

\section{(1) URI|}

valentão. Bully é um verbo que significa alarmar, acabrunhar, surgindo assim o substantivo bullying que é o fenômeno de violência entre pares (FANTE, 2008).

O bullying é qualificado como uma prática violenta que tem crescido espantosamente. É um conjunto de comportamentos agressivos, físicos ou psicológicos, como chutar, empurrar, apelidar e excluir (FANTE, 2005), que acontecem entre colegas, sem motivação aparente, sendo que geralmente um grupo de alunos ou um aluno com mais força, agride outro que não consegue encontrar um jeito para se defender (ANTUNES; ZUIN, 2008).

O Instituto Brasileiro de Geografia e Estatística (IBGE, 2016) apontou em pesquisas que $7,4 \%$ dos jovens afirmaram que na maior parte do tempo, ou quase sempre, se sentiram humilhados por provocações e que nos últimos trinta dias anteriores à pesquisa, 19,8\% dos estudantes disseram ter esculachado, zombado, mangado, intimidado ou caçoado. Os principais motivos das provocações dos colegas foram a aparência do corpo $(15,6 \%)$ e aparência do rosto $(10,9 \%)$.

Segundo Fante (2005), é de suma importância que os adolescentes sejam informados sobre o fenômeno e suas consequências, a partir das próprias experiências vividas, a fim de que percebam quais os pensamentos e as emoções acordadas por ele e, além disso, os principais motivos que levam a realizar esse tipo de prática, seja vítima, agressor ou espectador.

Ressalta-se que a família é considerada como a instituição que pode dar o suporte necessário e auxiliar a escola no sentido de promover o combate ao bullying. Manter os adolescentes em casa, isolados e distanciados da vida em sociedade, seus interesses estão voltados para atividades fora de casa, semelhante a não mais querer o convívio com a família, passando um menor tempo em contato íntimo com estes. Tornam-se secretos, distraídos, calados, fechados, em recolhimento, individualistas e apáticos. O desejo e o drama dos adolescentes é a incompreensão dos adultos; queixamse da incompreensão, mas mantém uma secreta aspiração de ser um fato impenetrável para qualquer adulto (DAVIM, 2009).

A pesquisa teve como objetivo, investigar as manifestações de bullying em estudantes do Ensino Médio de uma escola pública de uma cidade da região das 


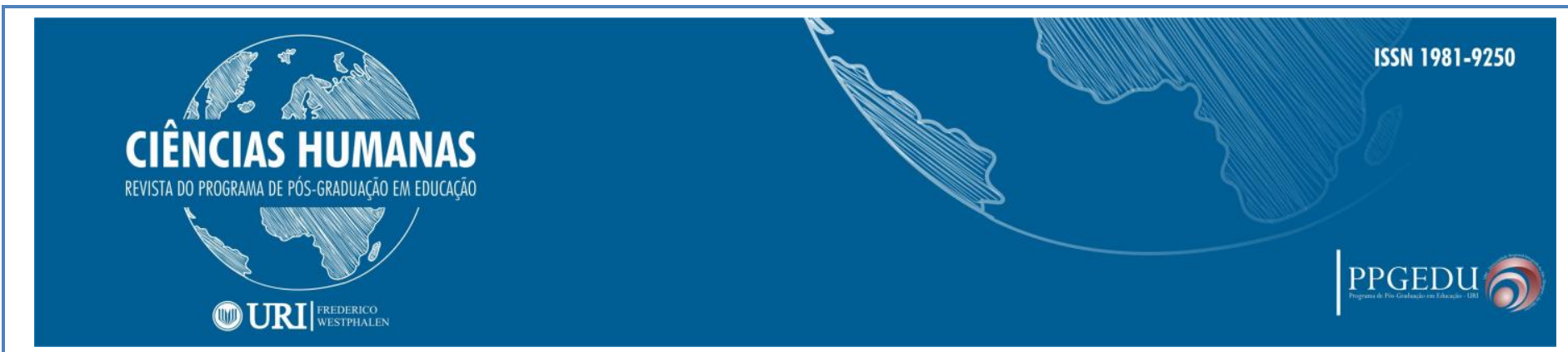

Missões/RS. Os objetivos secundários trataram de reconstruir teoricamente a trajetória do fenômeno bullying ao longo das últimas décadas escolares; identificar as diferentes manifestações do bullying em adolescentes do Ensino Médio nas aulas de Educação Física; compreender como se originam e se manifestam as ações de bullying em adolescentes do Ensino Médio e as consequências dessa prática nos aspectos físicos, psíquicos, emocionais, sexuais e espirituais; relacionar as manifestações de bullying nas aulas de Educação Física com aspectos culturais e sociais. A investigação partiu da seguinte problemática: quais experiências de bullying se manifestam nas aulas de Educação Física escolar com adolescentes do Ensino Médio?

\section{DECISÕES METODOLÓGICAS}

A pesquisa de caráter quanti-qualitativa foi realizada em uma escola pública de Ensino Médio de uma cidade da região das Missões/RS. Para Flick (2004), a pesquisa quanti-qualitativa se configura em uma das alternativas para ampliar a probabilidade de produção de resultados mais confiáveis, evitando distorções na análise e categorização dos dados coletados, pois " [...] as diferentes perspectivas metodológicas complementam-se no estudo do assunto, um processo que é entendido como a compensação complementar das deficiências e dos pontos obscuros de cada método isoladamente". (FLICK, 2004, p.274).

O estudo de caso é um método de pesquisa para a análise de realidade social. Ele envolve um processo de indagar, caracterizado pelo exame detalhado, abrangente, sistemático e em profundidade do caso objeto de estudo. O estudo de caso se caracteriza pela centralidade de uma situação, um evento, um programa ou um fenômeno em particular. É importante porque esse tipo de estudo revela questões sobre fenômeno e o que ele pode representar. Tal especificidade o torna capacitado para investigações que envolvem problemas práticos, questões, situações ou acontecimentos que surgem na vida diária. (SANDÍN ESTEBAN, 2010).

Para Deslandes e Gomes (2012) a entrevista é uma conversa entre dois indivíduos que se inicia com a iniciativa do entrevistador, com o objetivo de arquitetar

\begin{tabular}{l|l|l} 
Recebido em: 31/03/2019 & Aceito em: 26/04/2019 & Pg. $98-114$
\end{tabular}




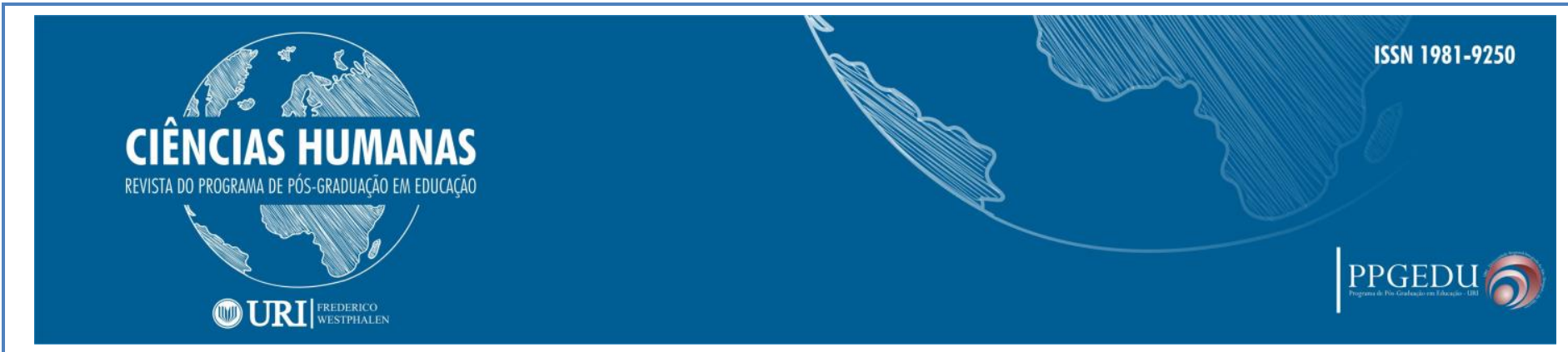

informações relacionadas para sua pesquisa. A entrevista semiestruturada é composta por perguntas abertas onde o entrevistado tem possibilidade em discorrer sobre $\mathrm{o}$ assunto sem se prender a perguntas formuladas.

Para a coleta de informações, inicialmente os pesquisadores entraram em contato com a escola para o consentimento e realização da pesquisa. Para se chegar aos sujeitos vítimas de bullying, primeiramente foi aplicado um questionário com adolescentes matriculados e frequentando os dois primeiros anos do Ensino Médio de uma escola pública de uma cidade da região das Missões/RS. O questionário foi composto de onze perguntas abertas e fechadas, sendo aplicados em cem estudantes. De posse dos questionários, foram identificados os estudantes que haviam sofrido bullying em aulas de Educação Física escolar, posteriormente, os estudantes foram convidados a participar da pesquisa mediante a assinatura e entrega do Termo de Consentimento e Assentimento Livre e Esclarecido. Dos treze sujeitos identificados, apenas quatro deles aceitaram participar da entrevista.

A compreensão das entrevistas ocorreu mediante a análise temática, que "[...] consiste em descobrir os núcleos de sentido que compõem uma comunicação cuja presença ou frequência signifiquem alguma coisa para o objeto analítico visado" (MINAYO, 2004, p. 209). Ainda segundo a mesma autora, a análise desdobra-se em três etapas: 1) pre-análise; 2) exploração do material; 3) tratamento dos resultados obtidos e interpretação.

Deste processo resultaram as seguintes categorias: manifestações de bullying por meio de violência verbal; manifestação de bullying por falta de habilidades corporais; e manifestações de bullying por meio de violência psicológica e moral (agressões relacionadas ao corpo). O presente estudo teve a aprovação do Comitê de Ética e Pesquisa da Universidade Regional Integrada do Alto Uruguai e das Missões - URI, Parecer $n^{\circ} 1.884 .516 \mathrm{dez} / 2016$. 


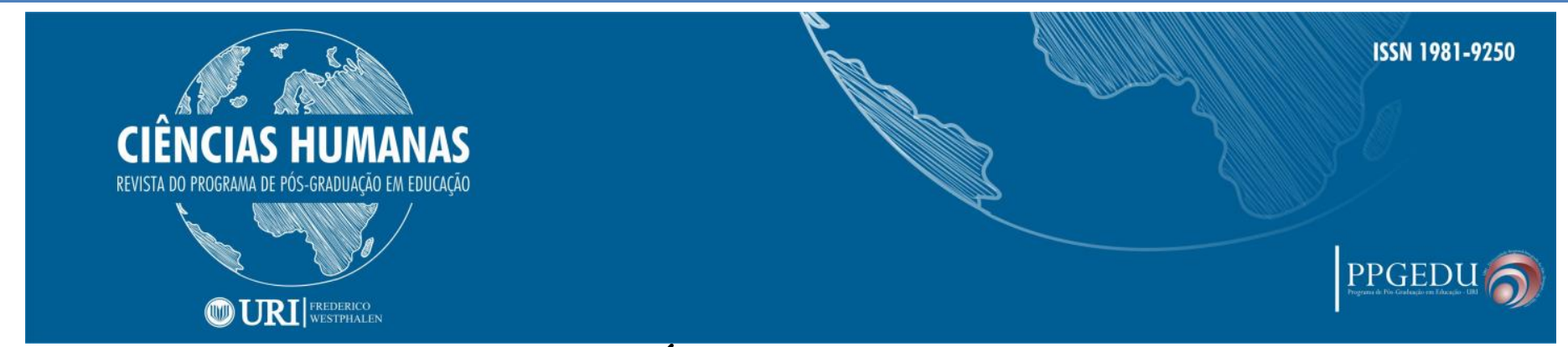

\section{O ENCONTRO COM AS VÍTIMAS}

Compreendendo os questionários, optou-se em quantificar apenas quatro questões relevantes para o estudo. A primeira questão indagou: você sabe o que é bullying? O gráfico 1 aponta que $92 \%$ dos estudantes responderam que sabiam o que é bullying e $8 \%$ que não sabiam. Dentre as respostas dadas pelos estudantes que responderam sim, estes disseram que bullying é quando outra pessoa faz brincadeiras de mal gosto ou piadas; alguém que sofre um tipo de perseguição por conta de sua aparência, cultura ou ideologia; bullying é uma agressão física ou verbal contra uma pessoa por algum tipo de preconceito.

Gráfico 1 - Você sabe o que é bullying?

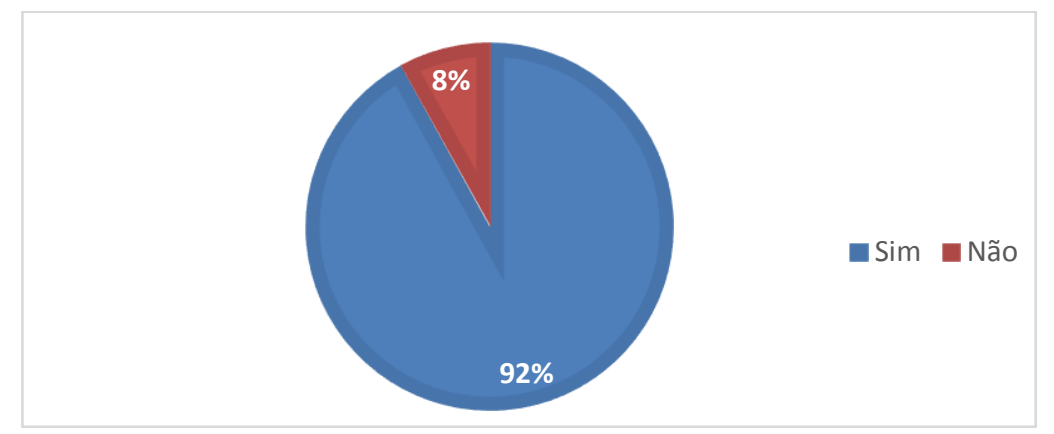

Fonte: Autoria própria (2019).

A segunda questão indagou: você já praticou algum tipo de bullying? No gráfico $19 \%$ dos estudantes responderam que sim, que já praticaram algum tipo de bullying e 81 $\%$ responderam que não praticaram nenhum tipo de bullying. Dentre as respostas dadas pelos estudantes que responderam sim, estes disseram que já praticaram bullying, como: quando era pequena apelidava alguns colegas; fico dando apelido e zoando dos amigos; apelidos maldosos; sim, mesmo não achando que era bullying, achando que era só brincadeira e a outra pessoa ficar ofendida. 


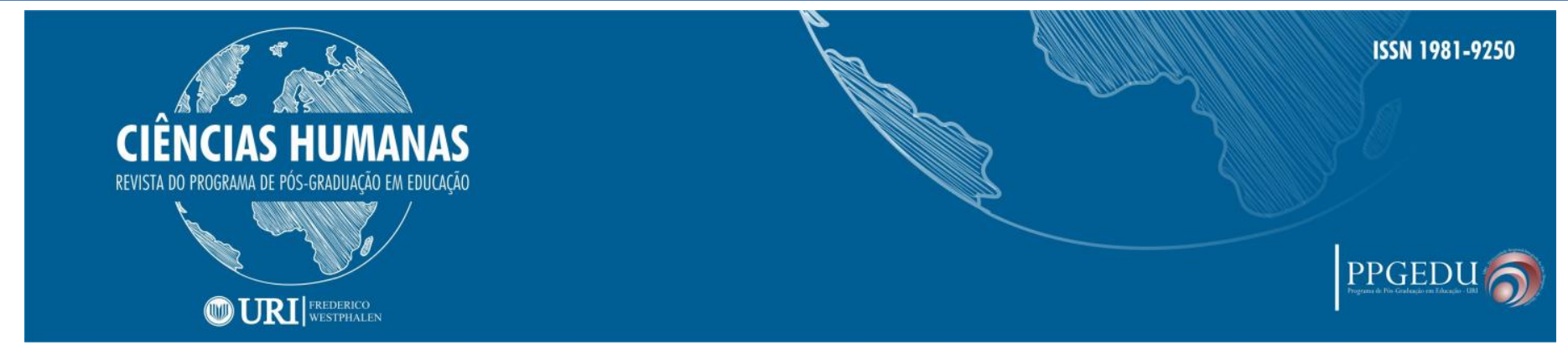

Gráfico 2 - Você já praticou algum tipo de bullying?

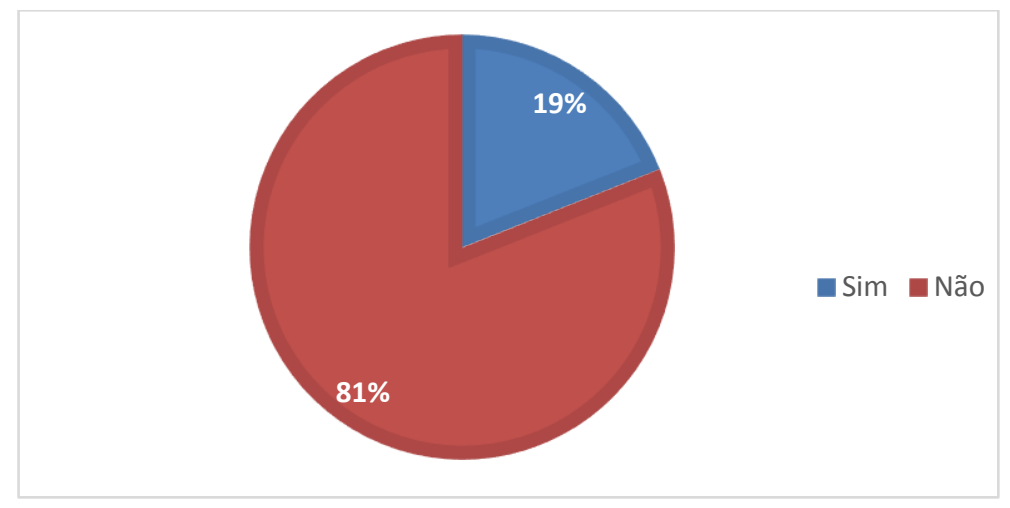

Fonte: Autoria própria (2019).

A terceira questão relevante questionava: você já sofreu algum tipo de bullying? $34 \%$ dos estudantes responderam que já sofreram algum tipo de bullying e $66 \%$ responderam que não sofreram nenhum tipo de bullying. Dentre as respostas dadas pelos estudantes que responderam sim, estes disseram que já sofreram algum tipo de bullying, como: apelidos de mal gosto; ser chamada de gorda e baixinha; em virtude do meu cabelo; apelidos maldosos.

Gráfico 3 - Você já sofreu algum tipo de bullying?

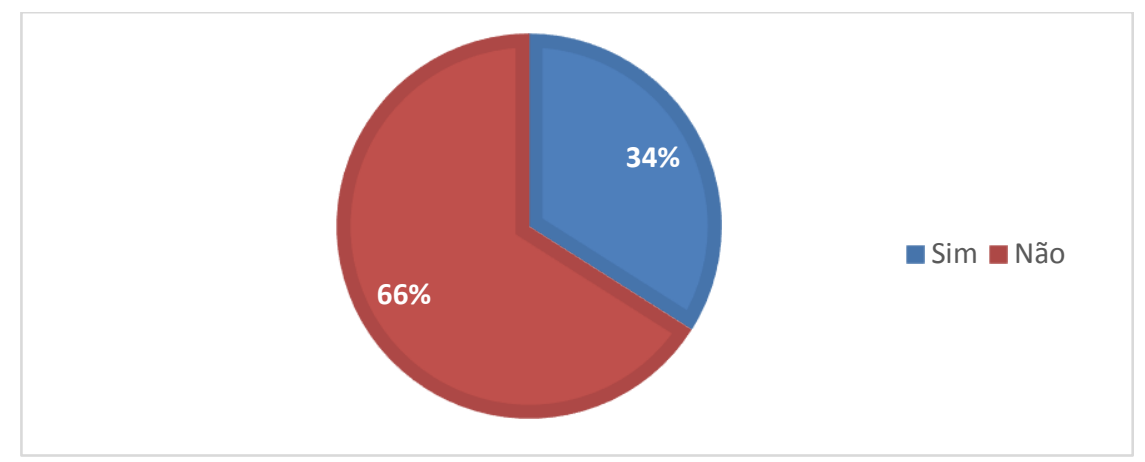

Fonte: Autoria própria (2019).

A quarta foi: você já foi vítima de bullying na Educação Física no Ensino Médio? 13\% dos estudantes responderam que já foram vítimas de bullying nas aulas de Educação Física e 87 \% responderam que não sofreram bullying. Dentre as respostas 


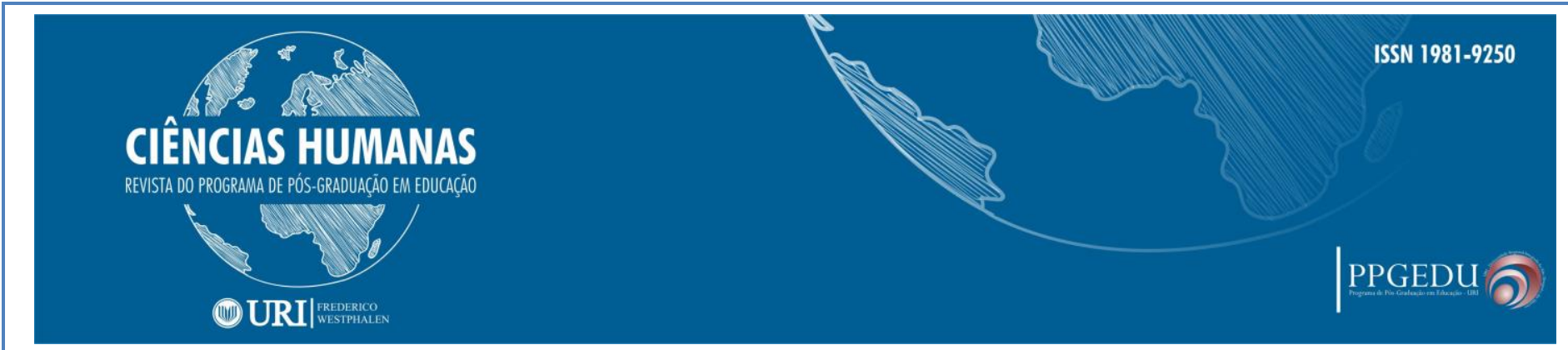

dadas pelos estudantes que responderam sim, estes disseram que já sofreram algum tipo de bullying na Educação Física, como: falavam que eu era ruim, que eu não jogava; preconceito com mulher jogando; por não saber jogar; fui chamado de ruim, podre.

Gráfico 4 - Você já foi vítima de bullying na Educação Física no Ensino Médio?

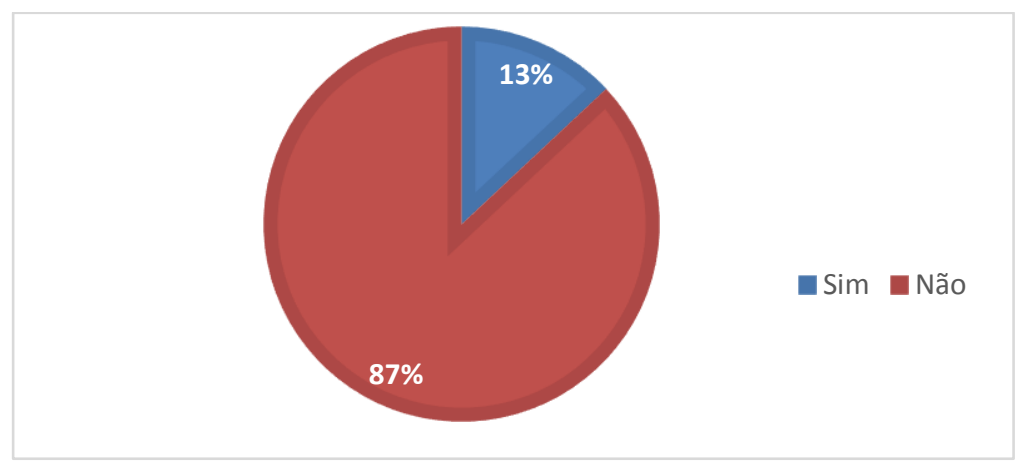

Fonte: Autoria própria (2019).

Após a aplicação do questionário, foram identificadas treze potenciais vítimas de bullying na Educação Física no Ensino Médio, apenas quatro estudantes trouxeram assinado o Termo de Consentimento Livre e Esclarecido fornecido aos pais e o Termo de Assentimento Livre e Esclarecido fornecido aos estudantes que participaram da entrevista de forma voluntária.

Os estudantes da pesquisa foram dois do gênero masculino e dois do gênero feminino. As entrevistas foram realizadas em dia, hora e local previamente marcado, entre pesquisador e estudantes garantindo o sigilo e a segurança dos mesmos. A pergunta disparadora foi: fale sobre sua Educação Física escolar. Os pesquisadores foram realizando outros questionamentos pertinentes ao assunto. A entrevista foi gravada e posteriormente transcrita de forma literal. Os estudantes receberam pseudônimos a fim de garantir o sigilo de suas identidades. Foram tratados aqui a partir da letra E que significa "Estudante" seguido de um número sequencial para identificação. 


\section{CIÊNCIAS HUMANAS}

REVISTA DO PROGRAMA DE PÓS-GRADUAĞ̈O EM EDUCAĞ̄o

\section{(10) URI|}

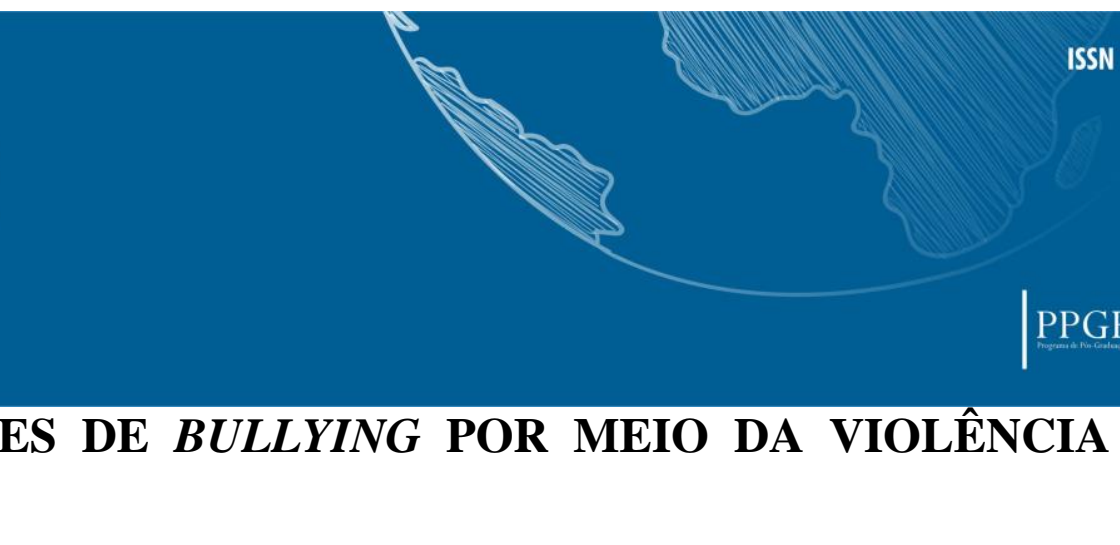

\section{MANIFESTAÇÕES DE BULLYING POR MEIO DA VIOLÊNCIA VERBAL}

As manifestações de bullying podem emergir de atitudes pretenciosas, geralmente carregadas com conteúdo pejorativo contribuindo para a exclusão social da vítima, como também, em muitos casos, pode ser o potencializador para a evasão escolar. A categoria busca dar visibilidade as falas dos estudantes, trazendo evidências de bullying a partir de comentários e expressões que caracterizem violência como: insultos, ofensas, xingamentos, gozações, apelidos pejorativos, entre outros (FANTE; PEDRA, 2008).

$\mathrm{Na}$ entrevista com o Estudante 1 (E1) ficou evidente o tom depreciativo e estigmatizante ao qual lhe foi dirigida a frase em aulas de Educação Física: "às vezes fui chamado de podre". Geralmente as vítimas de bullying são tímidas ou reservadas e não conseguem reagir aos comportamentos provocadores e inadequados dirigidas contra elas (FANTE; PEDRA, 2008). Em sua fala, o E1 revela: "fico na minha" e não revida as provocações, destaca também que quando chamam de "podre”, ele pára de jogar. Fante e Pedra (2008) alertam que essas vítimas apresentam dificuldades para se impor no grupo, tanto física, quanto verbalmente, tornando-se alvos fáceis e comuns dos ofensores. Outra questão que E1 aponta é que ele sofria bullying com mais frequência quando era criança, mas depois houve um período que considera como "tranquilo" quando ele conseguiu enturmar-se com os colegas. Silva (2010) afirma que a vítima geralmente é escolhida por apresentar uma "marca" que as difere da maioria dos estudantes. O estudante 1 era novato na escola e ainda não estava enturmado, tornandoo vulnerável.

Os estudos de Vianna e Souza (2015) afirmam que atos importunos como chateações hostis e, principalmente, agressividade em forma verbal, intencional e repetida, sem motivação aparente, provocados por um grupo ou mais de estudantes em relação a um indivíduo ou a um grupo, causa dor, angústia, exclusão, humilhação e discriminação. A violência verbal é denominada por Lopes e Saavedra (2004) como bullying direto, quando as vítimas são atacadas diretamente pelo agente ou pelos bullies

\begin{tabular}{l|l|l} 
Recebido em: 31/03/2019 & Aceito em: 26/04/2019 & Pg. 98 - 114
\end{tabular}




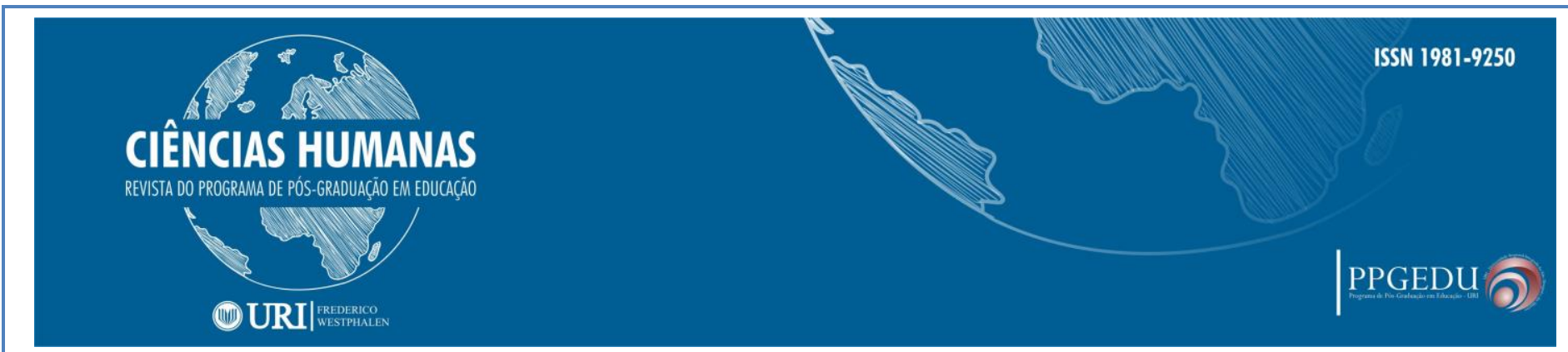

(agressores). São mais comuns ofensas verbais ou expressões, gestos, intimidações, humilhações, ameaças, difamações, opressões, discriminações, xingamentos, chacotas que geram mal-estar aos vitimizados. O bullying direto ocorre com frequência quatro vezes maior entre os meninos.

Nos comentários de Vianna e Souza (2015), que os atos verbais acontecem em meio a alunos, em ambiente escolar, pois geralmente não se tomam providências urgentes, de maneira que, com o passar do tempo, vão ferindo os sentimentos das vítimas com palavras agressivas e tomam proporções psicológicas graves. Geralmente o bullying atravessa as fronteiras das quadras e dos muros da escola, tornando um contexto social intermediado pelos agressores, pois esta "epidemia” já está disseminada. Lamentavelmente a prática se tornou tão popular que é admitida, na maioria das vezes, como natural, sendo habitualmente ignorada ou não valorizada, camuflando e abafando a panos quentes.

\section{MANIFESTAÇÕES DE BULLYING POR MEIO DAS INA HABILIDADES CORPORAIS}

A exposição corporal é uma característica marcante nas aulas de Educação Física, onde o corpo dos estudantes encontra-se em uma posição de vitrine, durante as práticas são exibidos, evidenciados por colegas, por olhares de fora e pelo professor. A categoria procura trazer evidências de manifestações do bullying a partir do viés das (ina) habilidades corporais, pois as vítimas podem sofrer por apresentar habilidades superiores ou inferiores aos pares.

O estudante 2 (E2) e estudante 3 (E3) sentem-se muito incomodados com o fato de não apresentarem habilidades específicas para o esporte futsal. Nas aulas de Educação Física, elas são ressaltadas - as execuções técnicas - e incentivadas na maioria das vezes pelos professores, que acabam excluindo os estudantes de algumas práticas. Tais atitudes reafirmam as limitações e tornam-se um "prato cheio" para os bulies que, identificando os menos habilidosos, são alvos fáceis de risos e piadinhas. O E2 fala que sofre bullying "porque não sabe jogar" e o E3 "quando erro algum passe, eles soltam aquelas piruadinhas".

\begin{tabular}{l|l|l} 
Recebido em: 31/03/2019 & Aceito em: 26/04/2019 & Pg. 98 - 114
\end{tabular}




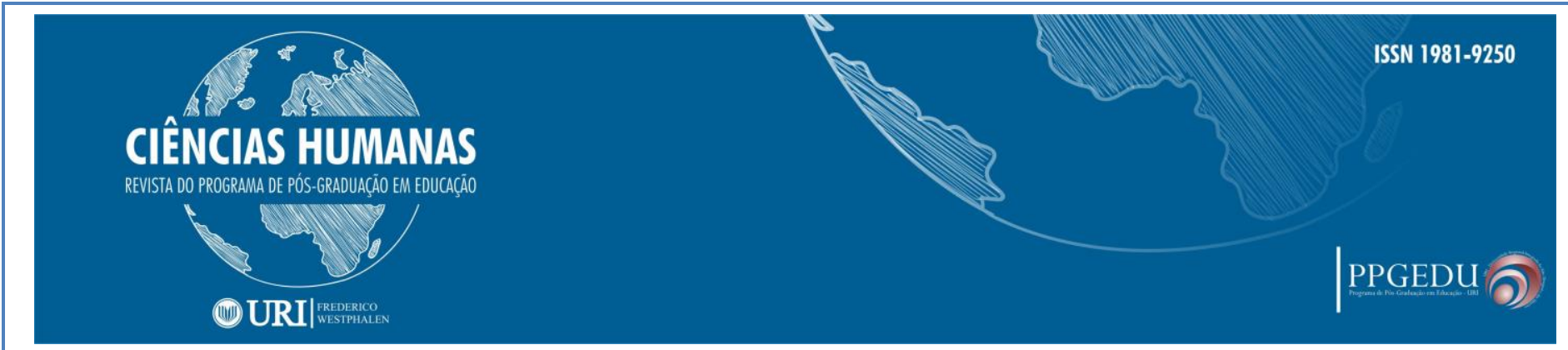

Os alunos que sofrem bullying reservam-se em seus movimentos corpóreos, pois recebem críticas dos colegas nas aulas de Educação Física. (PIRES, 2010). A autora corrobora afirmando que os alunos que não vibram com o movimento corpóreo, que se poupam nas demonstrações corporais, são chamados de "crianças velhas" e de acordo com suas observações, são os mais atingidos pelo fenômeno bullying, ao menos no componente Educação Física. O ensino da técnica em aulas de Educação Física escolar pode ser excludente e promover a seleção dos melhores, a partir disso, os estudantes que têm baixo desempenho físico, que não apresentam habilidades em determinados esportes se sentirão prejudicados, pois a má execução da técnica gerará "gozo" de estudantes mais habilidosos, comprometendo sua inserção nos grupos. Inclusive Furtado e Morais (2010) salientam que há um maior número de eventos associados ao bullying quando conteúdos são focados na competição.

As aulas de Educação Física escolar apresentam como característica principal a utilização de gestos técnicos específicos para a prática de determinados esportes. Esta tendência tecnicista do movimento esteve presente entre as décadas de 60 e metade dos anos 80 apresentava métodos, conteúdos, formas e meios à prática esportiva, com todas as suas normas, técnicas, táticas e busca de performances. O enraizamento desta tendência ainda pode ser evidenciado na formação de profissionais de Educação Física e apresenta-se fortemente valorizada na escola.

\footnotetext{
Uma técnica que é centrada no corpo, produz efeitos individualizantes, manipula o corpo como foco de forças que é preciso tornar úteis e dóceis ao mesmo tempo. E, de outro lado, temos uma tecnologia que, por sua vez, é centrada não no corpo, mas na vida; uma tecnologia que agrupa os efeitos de massas próprios de uma população. (FOUCAULT, 1999, p. 297).
}

Na perspectiva de Delunardo (2015) em seus estudos, casos de manifestações de bullying ocorridas em função da dificuldade apresentada por alguns alunos em atividades, pois a evidência colocada pelos colegas mais habilidosos se torna clara quando há pequenos erros dos alunos que não apresentam habilidades motoras e técnicas. Nas demonstrações e exemplos dados pelos professores predomina a execução de movimentos técnicos, onde os alunos mais habilidosos conseguem executá-los.

\begin{tabular}{l|l|r} 
Recebido em: 31/03/2019 & Aceito em: 26/04/2019 & Pg. 98 - 114
\end{tabular}




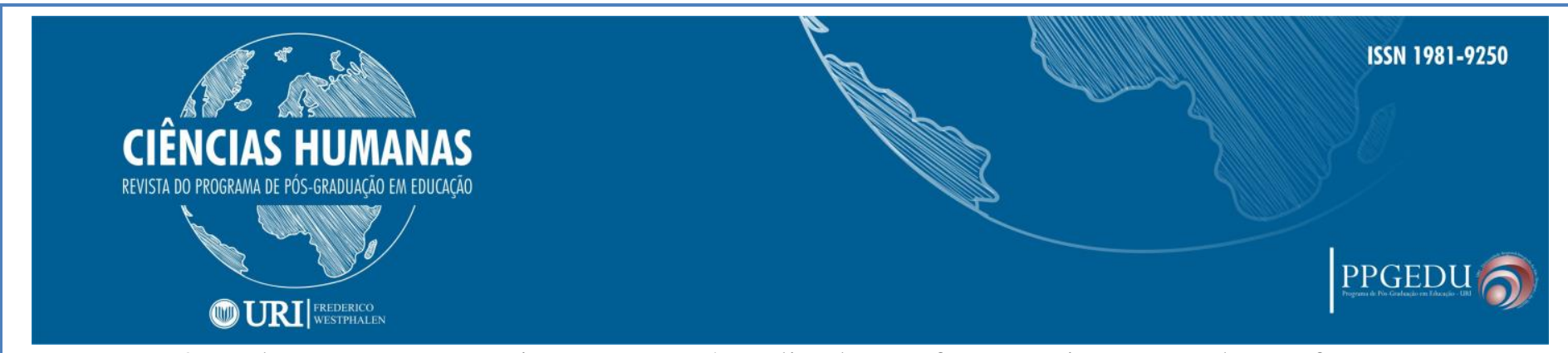

Quando o mesmo movimento não é realizado conforme a instrução do professor, iniciam os atos importunos, como chacotas, deboche, entre outros.

A padronização de determinados movimentos que exigem habilidades específicas também são recorrentes nas aulas de Educação Física. Em muitos casos acaba-se desvalorizando determinados repertórios corporais, onde os alunos menos habilidosos poderiam ser explorados, cabendo ao professor incentivar atividades que não estabeleçam a técnica como referência. Conforme Bomfim (2012) no cotidiano da Educação Física, condutas agressivas contra alunos que apresentam, no entendimento de seus pares, desempenho ineficaz, são motivadas pelo incentivo à competição.

Dialogando com os autores, é possível pontuar a relevância do professor diante dos casos de bullying. A postura a ser assumida por este no intuito de diversificar as atividades, ponderando o ensino das práticas corporais entre a técnica e o movimento espontâneo como possibilidade de ampliar o universo corporal nas aulas de Educação Física e na intermediação de conflitos gerados pelas inabilidades, de modo que o professor possa oferecer espaços para que cada um se manifeste de forma singular e plural.

\section{MANIFESTAÇÕES DE BULLYING POR MEIO DA VIOLÊNCIA PSICOLÓGICA E MORAL (CORPOREIDADE)}

O corpo contemporâneo, segundo Andrade (2012) é um corpo emergente, objeto de investimentos imperativos que se pautam na necessidade cada vez maior de agilidade e rapidez para não se tornar obsoleto. A categoria aborda questões relativas à violência produzida em torno do corpo, atacando e ferindo sistematicamente a saúde mental e moral dos estudantes.

O estudante 4 (E4) relata que "nasci com os pés virados para dentro, aí como eu fiz três cirurgias não posso forçar demais eles” e que “ evito joga assim pra não dar risada de mim”.

A Educação Física Escolar por meio dos estudos culturais direciona o olhar a condição humana por outra ótica, diferente, sobre a diversidade,

\begin{tabular}{l|l|l} 
Recebido em: 31/03/2019 & Aceito em: 26/04/2019 & Pg. 98 - 114 \\
\hline
\end{tabular}




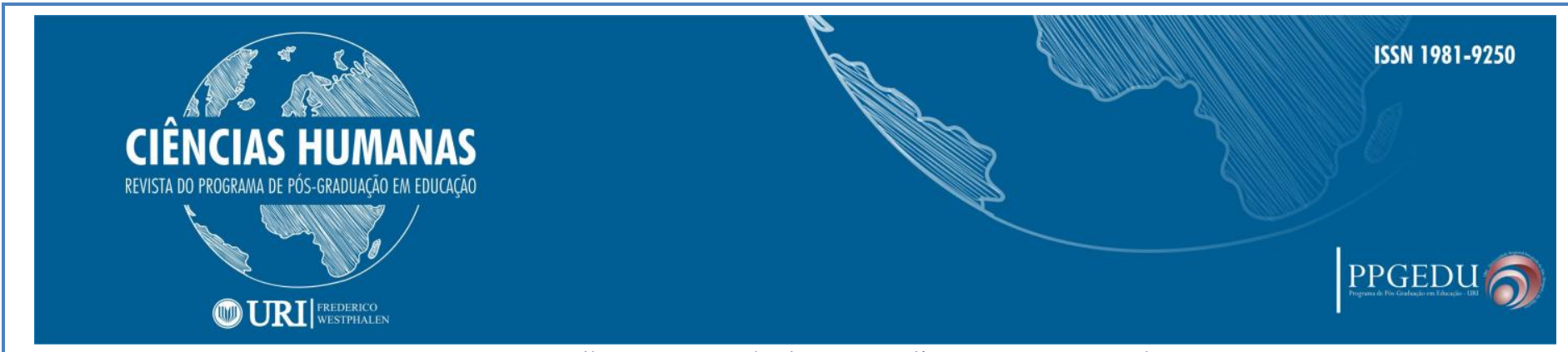

[...] olhar-se com óculos naturalistas para o ser humano, enxergam-se primeiramente semelhanças físicas entre os indivíduos. Qualquer ser humano do mundo possui a mesma constituição biológica que o torna humano. Em contrapartida, ao olhar-se com lentes das ciências humanas, pode-se enxergar as diferenças de todo o tipo presentes nos indivíduos. Todo ser humano é diferente de qualquer outro e único. (DAOLIO, 2010, p. 15).

Os meios de comunicação, a mídia, investem e valorizam a busca por corpos perfeitos, modismos, produtos e serviços para a melhoria da estética corporal. A Educação Física pode contribuir no sentido de dar suporte teórico, estabelecendo diálogos profícuos no sentido de que cada pessoa é diferente, é única e importante do seu modo de ser, pois a Educação Física pode desenvolver meios para que o estudante seja feliz no seu modo de ser, e que se sinta importante do como é, não deixando opiniões externas influenciar seu modo singular de ser.

A Educação Física não pode ser tratada como uma matéria simples no currículo escolar, sua função é elaborar atividades que envolvam o conhecimento sobre o corpo, jogos e brincadeiras, esporte, dança (atividade rítmica expressiva), ginástica, lutas e capoeira, para além do fazer, e não apenas com modalidades competitivas que despertem ou potencializem situações de violência (SILVA, 2014). O bullying corporal acontece muitas vezes em virtude de que as pessoas não conhecerem as diferenças entre os colegas, pois cada vez mais a sociedade persegue o estereótipo de corpo perfeito. O papel do professor torna-se fundamental a fim de explorar o universo da diferença e da tolerância, e evitar as violências e opressões corporais que crescem a cada instante.

A intolerância corporal está evidenciada na sociedade. É imprescindível alterar a base, mudando a concepção na escola, resgatando valores sociais e morais dos estudantes, defendendo o compromisso com a solidariedade e respeito humano, respeito às diferenças. Na escola a Educação Física deve atuar como coadjuvante nesse processo. É necessário alargar a compreensão de que o jogo se faz "a dois", e de que é diferente jogar "com" o companheiro e jogar "contra" o adversário, dessa forma instiga para que se possa pensar mais na coletividade, na solidariedade e no acolhimento às diferenças, sendo do corpo (físico), metal e outros (COLETIVO DE AUTORES, 1992).

\section{CONSIDERAÇÕES TRANSITÓRIAS}

A temática bullying nas aulas de Educação Física Escolar no Ensino Médio permitiu acessar histórias de vida de estudantes marcadas por algum tipo de violência: corporal, verbal,

\begin{tabular}{l|l|l}
\hline Rev. Ciências Humanas & Frederico Westphalen, RS & Jan./abr. 2019
\end{tabular}

\begin{tabular}{l|l|l} 
Recebido em: 31/03/2019 & Aceito em: 26/04/2019 & Pg. 98 - 114
\end{tabular}




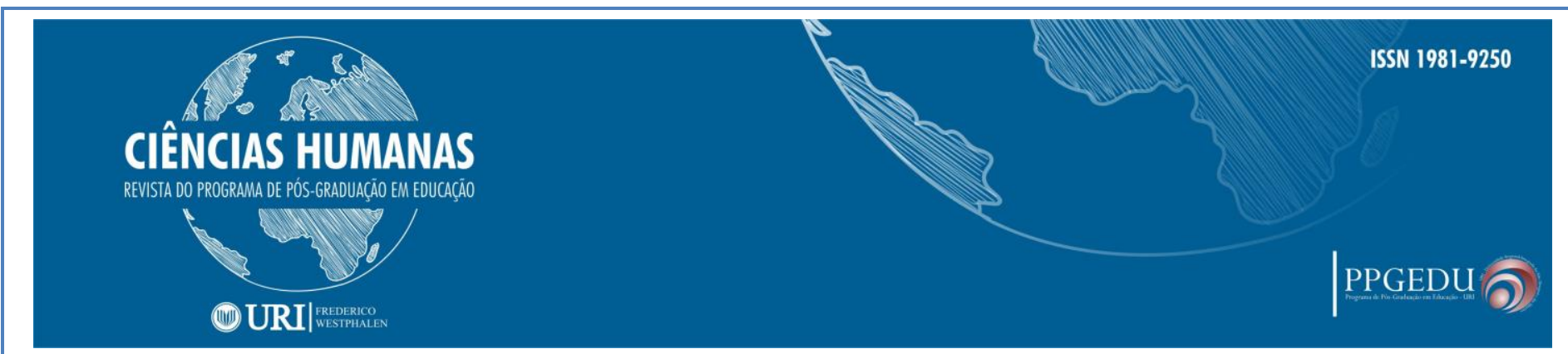

moral, psicológica, entre outras. Lendo, visitando e revisitando autores, foi possível a apropriação de significados e conhecimentos sobre este fenômeno violento que destrói, machuca e humilha pouco a pouco o interior das vítimas. Ao longo do artigo foi possível dar vez e voz para que as vítimas pudessem expressar suas experiências, assim como, desenvolveu-se empatia e compreensão dos acontecimentos que passam a fazer parte do dia a dia dos estudantes.

As entrevistas realizadas pelos (as) estudantes refletem as manifestações de bullying nas aulas de Educação Física Escolar no Ensino Médio e revelaram momentos e situações onde os alunos sofreram xingamentos e gozações de outros colegas em aulas. Os relatos mostram, mesmo que de forma limitada, o que pode acontecer dentro e fora de muitas escolas, comprovando que há a prática efetiva do fenômeno bullying.

Considera-se esta pesquisa relevante, pois cada vez mais o bullying é uma constante nas aulas de Educação Física. Urge a necessidade de frear o avanço desta prática nos cenários educativos para que não se torne "normal".

Por fim, com a descoberta dos focos de bullying nas aulas de Educação Física escolar no Ensino Médio, é imprescindível que se pense e se desenvolvam campanhas para combater o bullying, identificando-o a fim de que não interfira negativamente na vida familiar, escolar, social e laboral. Acredita-se que a escola, professores, família e estudantes devam unir-se e dialogar sobre o problema conjuntamente, buscando pessoas especializadas no assunto, elaborando ações e estratégias para combater as práticas de bullying nas escolas.

\section{REFERÊNCIAS}

ANDRADE, S.S. Mídia, corpo e educação: a ditadura do corpo perfeito. In: MEYER, E.E. Saúde, sexualidade e gênero na educação de jovens. Porto Alegre: Mediação, 2012.

ANTUNES, Deborah Christina; ZUIN, Antônio Alvares Soares. Do bullying ao preconceito: os desafios da barbárie à educação. Psicologia \& Sociedade, Porto Alegre, v. 20. n. 1, 2008. Disponível em: http://www.scielo.br/pdf/psoc/v20n1/a04v20n1.pdf. Acesso em: 18/11/2016.

ARMANI, A; SILVA, M.R; ROSA, C.T. Bullying - mais sério do que se imagina. Editora: EDIPUCRS, 2008.

BOMFIM, D. L. et al. Ocorrência de bullying nas aulas de educação física em uma escola do Distrito Federal. Pensar a Prática, Goiânia, v. 15, n. 2, 2012. Disponível em: https://revistas.ufg.br/fef/article/view/12520/11202. Acesso em: 18/11/2016.

\begin{tabular}{l|l|r} 
Recebido em: 31/03/2019 & Aceito em: 26/04/2019 & Pg. 98 - 114
\end{tabular}


COLETIVO DE AUTORES. Metodologia do ensino da Educação Física. São Paulo: Cortez, 1992.

DAOLIO, Jocimar. A Educação Física Escolar como prática cultural: tensões e riscos. In: DAOLIO, Jocimar (Org). Educação Física Escolar: olhares a partir da cultura. São Paulo: Ed. Campinas, 2010.

DAVIM, R. M. B. et.al. Adolescente/Adolescência: revisão teórica sobre uma fase crítica da vida. Rev. Rene, Fortaleza, v. 10, n. 2, p. 131-140, abr./jun. 2009.

DELUNARDO, C.S. Bullying na educação física escolar: a visão de professores da educação básica. Cadernos UniFOA, Volta Redonda, n. 29, p. 115-128, dez. 2015.

DESLANDES, S. F; GOMES, R. Pesquisa Social teoria, método e criatividade. 32. Ed. Petrópolis, RJ: Vozes, 2012.

FANTE, Cleo. Fenômeno bullying: como prevenir a violência nas escolas e educar para a paz. Campinas: Verus Editora, 2005.

FANTE, C; PEDRA, J. Bullying escolar: perguntas e respostas. Porto Alegre: Artmed, 2008.

FOUCAULT, Michel. Em defesa da sociedade: curso no College de France (19751976). São Paulo: Martins Fontes, 1999.

FURTADO, D.S; MORAIS, P.J.S. Bullying nas aulas de educação física e o papel do professor. Revista Digital EFDeportes.com, Buenos Aires, ano 15, n.147, 2010. Disponível em https://www.efdeportes.com/efd147/bullying-nas-aulas-de-educacaofisica.htm. Acesso em 22/11/2016.

FLICK, Uwe. Introdução à pesquisa qualitativa. Porto Alegre: Artmed, 2004.

IBGE. Instituto Brasileiro de Geografia e Estatística. Bullying. Disponível em: http://teen.ibge.gov.br/especiais-teen/pense/pense-pag-7.html Acesso em: 18/11/2016.

LOPES, N. A. A.; SAAVEDRA, L. H. Diga NÃO para o bullying. Rio de Janeiro: ABRAPIA, 2004.

MALTA, D. C. et al. Bullying nas escolas brasileiras: resultados da Pesquisa Nacional de Saúde do Escolar (PeNSE), 2009. Ciência \& Saúde Coletiva, Rio de Janeiro, v. 15, n. 2,2010 .

MINAYO, M. O desafio do conhecimento: pesquisa qualitativa em saúde. São Paulo: Hucitec-Abrasco, 2004.

\begin{tabular}{l|l|r} 
Recebido em: 31/03/2019 & Aceito em: 26/04/2019 & Pg. $98-114$
\end{tabular}




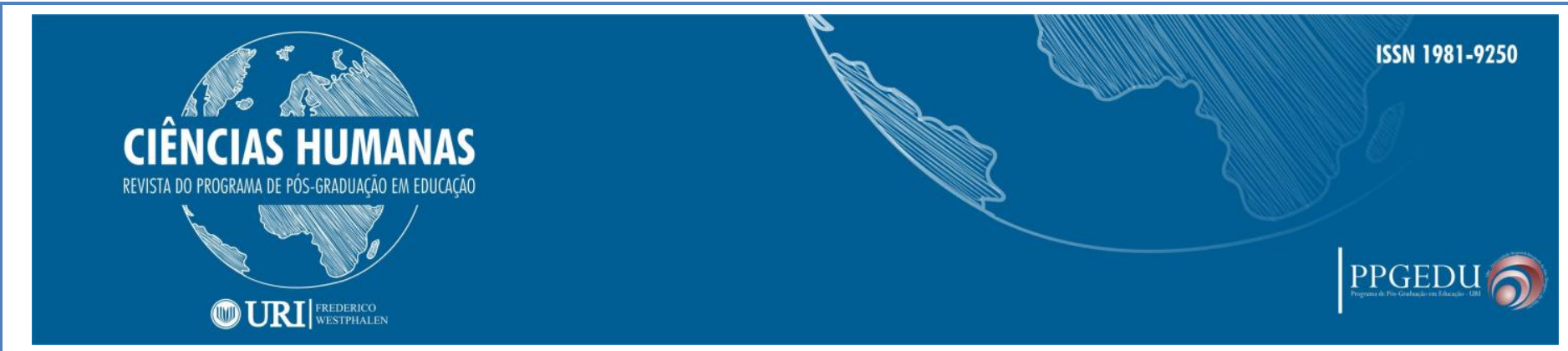

OLIVEIRA, F. F.; VOTRE, S. J. Bullying nas aulas de educação física. Revista Movimento, Porto Alegre v. 12, n. 2, p. 173-197, 2006.

PESTANA, S. M. A. B. Educação Física no Ensino Médio: uma proposta pedagógica. Disponível

em:

http://www.confef.org.br/extra/revistaef/arquivos/2002/n04_setembro/06_educacao_fisi ca_no_ensino_medio.pdf. Acesso em: 11/10/2015.

PIRES, M.J. Bullying escolar: a corporeidade como fator de in/exclusão sócioeducacional. Dissertação de Mestrado. Ijuí: Ed. Unijuí, 2010.

SANDÍN ESTEBAN, M. P. Pesquisa qualitativa em educação: fundamentos e tradições. Porto Alegre: AMGH, 2010.

SILVA, Ana Beatriz Barbosa. Mentes perigosas nas escolas: bullying. Rio de janeiro: Ed. Objetiva, 2010.

SILVA, Rozemeire Pinheiro da. Jogos cooperativos como estratégia de redução da violência nas aulas de educação física: um estudo de caso em Barra do Bugres - MT. Universidade de Brasília, Barra do Bugres, 2014.

VIANNA, José Antônio Viana; SOUZA, Silvana Márcia de Souza; REIS, Katarina Pereira dos. Bullying nas aulas de Educação Física: a percepção dos alunos no Ensino Médio. Ensaio: aval. pol. públ. Educ. Rio de Janeiro, v. 23, n. 86, p. 73-93, jan./mar. 2015. 
